\title{
Erratum to: Cost of a lymphedema treatment mandate-10 years of experience in the Commonwealth of Virginia
}

Robert Weiss

\section{Erratum}

Unfortunately both the HTML and the PDF versions of this article [1] on the SpringerOpen web site contained typographical errors in the superscripted citations to the list of footnotes/endnotes and in some hyperlinks to tables. Two URLs to the data reports have been expanded to take the reader directly to the full set of mandated annual reports without further searching. 


\section{Changes to in-text citations in HTML Version}

\begin{tabular}{|c|c|c|}
\hline Section or Subsection Title & Containing Text & Corrected Text \\
\hline CPT and ICD-9-CM codes collected & ...reporting rules ${ }^{2,3}$ require ... & ...reporting rules ${ }^{2,3}$ require ... \\
\hline Insured population & $\ldots$ Care Act of 2010 & $\ldots$ Care Act of $2010^{12}$ \\
\hline Insured population & ...Bureau report in 2013. & ...Bureau report in $2013^{13}$. \\
\hline Virginia pre-mandate analysis & Virginia pre-mandate analysis & Virginia pre-mandate analysis ${ }^{6}$ \\
\hline California mandate analysis & California mandate analysis & California mandate analysis ${ }^{5}$ \\
\hline Massachusetts mandate analysis & Massachusetts mandate analysis & Massachusetts mandate analysis ${ }^{7}$ \\
\hline North Carolina ....mandate & North Carolina ... mandate & North Carolina ....mandate ${ }^{8}$ \\
\hline Benefits of lymphedema treatment & The California analysis ${ }^{9}$ author.. & The California analysis ${ }^{5}$ author.. \\
\hline Completeness of reported mandate. & Reporting instructions ${ }^{12}$ require & Reporting instructions ${ }^{3}$ require \\
\hline Completeness of reported mandate ... & ... from about 70 to $85 \%^{13}$. & ...from about 70 to $85 \%^{14}$. \\
\hline Completeness of reported mandate ... & ... to lymphedema treatment ${ }^{14}$. & ... to lymphedema treatment. \\
\hline
\end{tabular}

Deletion of hyperlinks in HTML version to tables in other documents

\begin{tabular}{lll}
\hline Section or Subsection Title & Containing Text & Corrected Text \\
Population Coverage & $\ldots$ on Table 3 - of reference [4]. & $\ldots$ on Table 3 of reference [4]. \\
Preliminary mandate commission $\ldots$ & $\ldots$ as Table $\underline{3}$ of Ref. 4. & $\ldots$ as Table 3 of Ref. [4]. \\
\hline
\end{tabular}

\section{Correction of URLs in HTML version}

In Table 1, URL should be: http://leg2.state.va.us/DLS/

h\&sdocs.nsf/Search+All/?SearchView\&SearchOrder $=4 \& q u-$

ery $=38.2-3419.1$

In Footnote 4, URL should be: http://leg2.state.va.us/ DLS/h\&sdocs.nsf/Search+All/?SearchView\&earchOr-

der $=4 \&$ query $=38.2-3419.1$

Changes to in-text citations in PDF Version

\begin{tabular}{|c|c|c|}
\hline Section or Subsection Title & Containing Text & Corrected Text \\
\hline Annual data reports & ....in place a statute that requires & ... in place a statute ${ }^{3}$ that requires \\
\hline Annual reports to the VA governor & ....insurance, and $\mathrm{HMOs}^{3} \ldots$ & $\ldots$ insurance, and $\mathrm{HMOs}^{4} \ldots$ \\
\hline Benefits of lymphedema treatment & The California analysis ${ }^{4}$ author.. & The California analysis ${ }^{5}$ author.. \\
\hline Completeness of reported mandate. & Reporting instructions ${ }^{11}$ require & Reporting instructions ${ }^{10}$ require \\
\hline Completeness of reported mandate ... & ...from about 70 to $85 \%^{12}$. & ...from about 70 to $85 \%^{14}$. \\
\hline Completeness of reported mandate. & $\ldots$ to lymphedema treatment ${ }^{14}$. & ... to lymphedema treatment. \\
\hline
\end{tabular}

\section{Correction of URLs in PDF version}

In Table 1, URL should be: http://leg2.state.va.us/DLS/ h\&sdocs.nsf/Search+All/?SearchView\&SearchOrder $=4 \& q u-$ ery $=38.2-3419.1$

In Endnote 2, URL should be: http://leg2.state.va.us/DLS/ h\&sdocs.nsf/Search+All/?SearchView\&SearchOrder $=4 \& q u-$ ery=38.2-3419.1

In Endnote 11, URL should be: http://www.heritage.org/ research/testimony/2013/06/health-care-consolidation- and-competition-after-ppaca. Accessed on September 13, 2016.

Received: 14 September 2016 Accepted: 22 September 2016 Published online: 19 October 2016

\section{Reference}

1. Weiss R. Cost of a lymphedema treatment mandate-10 years of experience in the Commonwealth of Virginia. Health Economics Review. 2016;6:42. 